\title{
Effects of amniotic membrane on epithelial wound healing and stromal remodelling after excimer laser keratectomy in rabbit cornea
}

\author{
H-M Woo, M S Kim, O-K Kweon, D-Y Kim, T-C Nam, J H Kim
}

\begin{abstract}
Aims-To investigate if the amniotic membrane (AM) promotes epithelial migration while inhibiting stromal remodelling associated with corneal haze after excimer laser keratectomy.

Methods-A wound $150 \mu \mathrm{m}$ in depth and $6.0 \mathrm{~mm}$ in diameter was produced in 40 rabbits using an excimer laser. One eye was randomly chosen to be covered by the AM while the other eye served as a control. Epithelial wound healing was evaluated, together with any morphological changes of the anterior stroma connected with corneal haze. These morphological changes were histopathologically analysed using dichlortriazinyl aminofluorescein (DTAF), Masson trichrome staining, and an image analyser.

Results-The AM group had a short latent phase followed by fast epithelial healing $(p<0.001)$ during the early wound healing period and a significant decrease in the inflammatory response, together with a smaller change in the number of keratocytes than the control group. The mean thickness of the regenerated stroma was significantly thinner in the AM group than in the control group at 8 weeks $(p<0.0001)$. The AM group had a more regular architecture of regenerated stromal lamella at 8 weeks and significantly less haze after 4 weeks than the control group $(p<0.05)$.

Conclusion-Use of the AM as a dressing on a corneal wound created by excimer laser surgery, in which severe haze is expected, may induce rapid epithelial healing with less inflammatory response. The AM may inhibit the irregular synthesis of stromal collagen that is associated with corneal haze.
\end{abstract}

(Br F Ophthalmol 2001;85:345-349)

The excimer laser has been used for the correction of myopic refractive error (photorefractive keratectomy, PRK) and for the treatment of superficial corneal opacification and surface irregularities (phototherapeutic keratectomy, PTK). ${ }^{1-7}$ Although both technical and clinical advances have been made in the application of excimer lasers to the cornea, ${ }^{1-4}$ the scattering of light that follows regeneration of the corneal stromal tissue can interrupt visual improvement after surgery. ${ }^{5-7}$ The severity of corneal haze is thought to be influenced by the amount of attempted correction, especially in patients undergoing deep stromal photoablation, $^{2}$ and may be related to the amount of regenerated stroma. ${ }^{3}$

To reduce corneal haze following photoablation, attempts have been made to simulate the wound healing process. ${ }^{8-13}$ Topical steroids were found to inhibit haze ${ }^{89}$ while the presence of the epithelium ensured rapid wound healing with minimal tissue proliferation. ${ }^{10}$ The repopulated stromal keratocytes after a corneal wound subsequently synthesise collagen and extracellular matrix during stromal remodelling, both of which may be associated with the development of corneal haze and a change in clinical refraction. ${ }^{311-13}$ The ideal result of corneal wound healing following photoablation would therefore be rapid reconstruction of the corneal epithelium with minimal stromal remodelling.

In recent years the amniotic membrane (AM) has been used as a treatment substrate for reconstruction of the ocular surface in patients with limbal stem cell deficiency or a persistent epithelial defect. ${ }^{14}{ }^{15}$ More recently, high levels of several growth factors (basic fibroblast growth factor (b-FGF); epidermal growth factor (EGF); keratocyte growth factor (KGF); hepatocyte growth factor (HGF)) known to modulate the wound healing response have been detected in preserved human $\mathrm{AM},{ }^{16}{ }^{17}$ and it is thought that the high level of EGF present in the AM may be one reason for its use as a dressing for re-epithelialisation after a corneal wound. In addition, Tseng $e t a l^{18}$ have shown that an AM matrix can suppress the transforming growth factor (TGF)- $\beta$ signalling system, DNA synthesis, and subsequent myofibroblast differentiation. Furthermore, Choi et $a l^{12}$ have reported that application of AM reduces keratocyte proliferation and corneal haze after PRK. However, as yet the effect of the AM on epithelial migration - which is one of the most important biological responses of corneal wound healing - has not been determined. Also, it is unknown whether the AM inhibits stromal regeneration which is known to affect the development of undesirable haze after excimer laser treatment.

A study was therefore undertaken to investigate the effects of the AM on corneal wound healing in connection with epithelial migration and to study any histological changes of the stroma in the ablated zone using dichlortriazinyl aminofluorescein (DTAF), Masson trichrome staining, and an image analyser. 


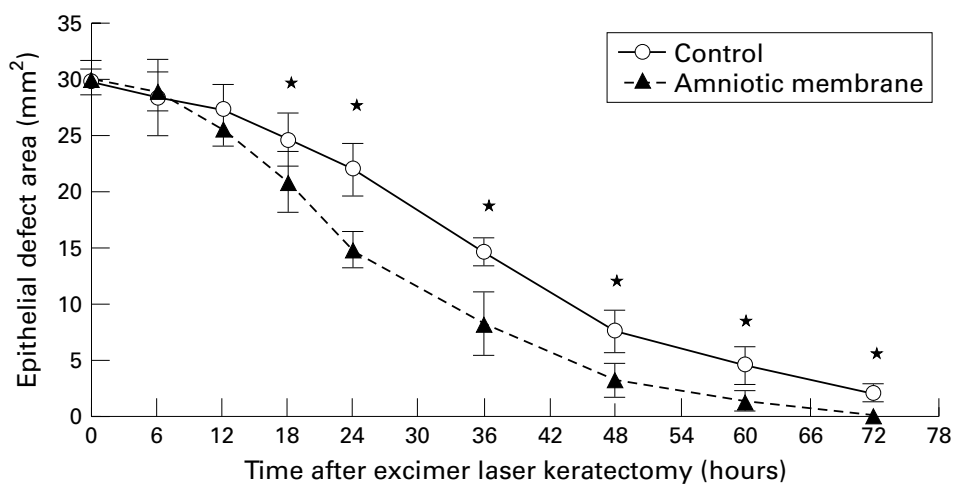

Figure 1 Changes in epithelial defect area after excimer laser keratectomy compared with control group. Values are mean $(S D) .{ }^{*} p<0.01$.

Table 1 Mean (SD) epithelial healing rates per hour after excimer laser keratectomy

\begin{tabular}{llll}
\hline Time after surgery & $\begin{array}{l}\text { Control group } \\
(\mu m ; n=10 \text { eyes })\end{array}$ & $\begin{array}{l}\text { AM group } \\
(\mu m ; n=10 \text { eyes })\end{array}$ & $p$ value \\
\hline $0-6$ & $12.9(9.4)$ & $10.3(2.3)$ & NS \\
$6-12$ & $9.1(4.1)$ & $30.6(3.6)$ & 0.0002 \\
$12-18$ & $24.5(3.5)$ & $46.7(7.1)$ & 0.007 \\
$18-24$ & $26.2(2.7)$ & $67.0(6.1)$ & 0.0001 \\
$24-36$ & $40.3(2.4)$ & $48.0(6.9)$ & NS \\
$36-48$ & $50.9(4.0)$ & $52.9(7.4)$ & NS \\
$48-60$ & $29.6(4.3)$ & $29.5(4.3)$ & NS \\
$60-72$ & $30.8(3.0)$ & $43.7(7.9)$ & NS \\
Lag phase $(\mathrm{h})$ & $13.2(3.8)$ & $5.4(1.9)$ & $<0.001$ \\
Mean rate $(\mu \mathrm{m}) \dagger$ & $35.8(1.3)$ & $44.6(1.9)$ & $<0.001$ \\
\hline
\end{tabular}

$\mathrm{AM}=$ amniotic membrane; $\mathrm{NS}=$ not significant.

The rates were calculated by the decrease in wound radius.

*Student's $t$ test.

$\dagger$ Mean rate excluded a latent phase.

\section{Materials and methods}

AM PREPARATION

The AM was collected and kept according to the method of Kim and Tseng ${ }^{19}$ with minor modifications. The AM was separated from the chorion of the placenta and obtained immediately following caesarean deliveries. Under a lamella flow hood the AM was thoroughly washed with a phosphate buffered saline solution ( $\mathrm{pH} 7.2$ ) containing gentamicin $8 \mu \mathrm{g} /$ $\mathrm{ml}$ and cefaxoline $4 \mu \mathrm{g} / \mathrm{ml}$. It was then attached to a nitrocellulose membrane by placing the epithelium side to the top, and further cut into $1.5 \mathrm{~cm}$ diameter discs. The AM was stored at $-20^{\circ} \mathrm{C}$ in Dulbecco's modified Eagle medium containing glycerin (Life Technology Inc, NY, USA) in a ratio of $1: 1$ ( $\mathrm{vol} / \mathrm{vol})$.

EXCIMER LASER PHOTOTHERAPEUTIC

KERATECTOMY

Forty New Zealand white rabbits with clinically normal eyes weighing $2.5-3.0 \mathrm{~kg}$ were used in the experiment. A wound $6 \mathrm{~mm}$ in diameter with a depth of $150 \mu \mathrm{m}$ was created in the centre of the cornea using a $193 \mathrm{~nm}$ excimer laser (VISX Star Inc, CA, USA).

\section{AM GRAFT}

The AM was washed thoroughly and immersed in $0.9 \%$ saline solution containing gentamicin $8 \mu \mathrm{g} / \mathrm{ml}$ and cefaxoline $4 \mu \mathrm{g} / \mathrm{ml}$ for 30 minutes before surgery. Immediately after PTK one eye was randomly covered with the preserved AM with the stromal side facing the ablated corneal surface. The other eye served as the control. The AM was then secured with a pursestring episcleral fixation suture $2 \mathrm{~mm}$ behind the limbus using $8 / 0$ polyglactin 910 (Vicryl). Ofloxacin (Samil Pharmaceuticals, Korea) topical drops were applied to all eyes three times daily for 1 week. Three days after surgery the AM was carefully removed.

DETERMINATION OF EPITHELIAL HEALING TIME Time measurements for wound closure were determined from photographs taken of the defective area at 6 hour intervals for the first 24 hours and then at 12 hour intervals for the next 72 hours after surgery. All photographs were taken at a fixed focus length with the slit lamp (Topcon, Japan) under a cobalt blue filter.

Outlines of the defective areas were measured with an image analyser (Quantiment 520, Cambridge Co, UK). To compare the defective areas quantitatively the spherical areas were calculated from these measurements using the formula of Crosson et al..$^{20}$ The healing rates were expressed in regression rates of radius per hour.

ASSESSMENT OF CORNEAL HAZE

The degree of corneal haze produced was measured on days 1 and 3 and again 1, 2, 4, 6, and 8 weeks after surgery by slit lamp microscopic examination. Corneal haze was graded as defined by Fantes et al. ${ }^{21}$ When there was a difference of opinion on the density grading the mean value was used. However, where there was a difference of more than 0.5 grades between two observers the results were omitted from the statistical analysis.

INFLAMMATORY CELL INFILTRATION AND

KERATOCYTES IN THE STROMA

Six corneas were collected for histopathological examination on days 1 and 3 and again 2, 4, and 8 weeks after surgery. The histological sections were cut to a thickness of $4 \mu \mathrm{m}$ through the centre of the cornea and stained with haematoxylin-eosin. The sections were examined under the light microscope (Axioscope, Zeiss, Germany) and photographed digitally with a cooled CCD camera (Micromax Kodak 1317, Princeton Instruments, Tucson, AZ, USA). The numbers of inflammatory cells and keratocytes were counted manually and calculated per $10000 \mu \mathrm{m}^{2}$ area of the surgical sites with a computer assisted image analysis system (Metamorph, Universal Imaging Co, West Chester, PA, USA). Calculations were performed in four different sites - two in the middle and two at the periphery of the surgical area. The mean (SD) numbers of cells from four calculations are presented.

\section{REGENERATED CORNEAL STROMAL THICKNESS} AND ARRANGEMENT

Postoperatively the de-epithelialised and ablated stromal beds were bathed in a fresh solution of $0.5 \%$ dichlortriazinyl aminofluorescein (DTAF) dye (Molecular Probes Inc, USA) mixed with $0.2 \mathrm{~mol} / 1$ sodium bicarbonate buffer for 60 seconds. DTAF is progressively dispersed over a greater area, consistent with regeneration of the tissue, without complete turnover during wound healing. ${ }^{22} 23$ Some sections from six extracted eyes from each 


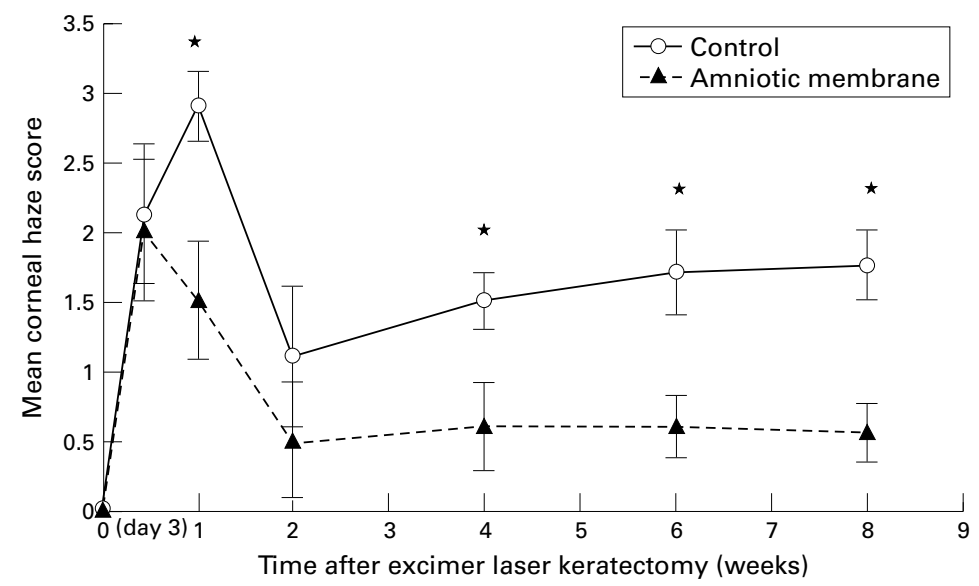

Figure 2 Mean (SD) corneal haze scores after excimer laser keratectomy compared with control group. ${ }^{*} p<0.05$.
Table 3 Mean (SD) number of keratocytes in epithelium after excimer laser keratectomy

\begin{tabular}{|c|c|c|c|}
\hline $\begin{array}{l}\text { Time after } \\
\text { surgery }\end{array}$ & $\begin{array}{l}\text { Control group } \\
(n=6 \text { eyes })\end{array}$ & $\begin{array}{l}\text { AM group } \\
(n=6 \text { eyes })\end{array}$ & $p$ valuef \\
\hline 1 day & $2.7(0.8)$ & $8.8(0.8)$ & $<0.0001$ \\
\hline 3 days & $3.3(0.3)$ & $9.9(1.0)$ & 0.0001 \\
\hline 2 weeks & $15.0(0.7)$ & $13.3(0.9)$ & NS \\
\hline 4 weeks & $19.6(1.3)$ & $14.7(0.5)$ & 0.0027 \\
\hline 8 weeks & $24.7(1.9)$ & $16.4(1.5)$ & $<0.0001$ \\
\hline
\end{tabular}

The mean duration of the latent phase was shorter in the AM group than in the control group (Table 1). The rates in the AM group were significantly higher than those in the control group from 6 to 24 hours.

\section{CORNEAL HAZE}

The corneal haze was most intense on day 3 and improved markedly by 2 weeks postoperatively, but remained almost unchanged by 8 weeks in the AM group (Fig 2). However, after 4 weeks the degree of corneal haze in the AM group was significantly less severe than that of the control group $(\mathrm{p}<0.05)$.

\section{INFLAMMATORY CELL INFILTRATION AND}

KERATOCYTES IN THE STROMA

On day 1 after surgery the anterior stroma without epithelium was infiltrated with many polymorphonuclear granulocytes (PMNs) and on day 3 after surgery there were few keratocytes around the inflammatory cells infiltrated in the anterior stroma. The inflammatory cells were infiltrated deeply in the control corneas. The number of inflammatory cells was considerably lower in the AM group than in the control group (Table 2).

Changes in the keratocytes observed after surgery in both groups are shown in Table 3. In the AM group the number of keratocytes within the stroma beneath the ablated zone was greater than that of the control group on days 1 and 3 after surgery. After 2 weeks an increased number of keratocytes below the epithelium was noted in both groups. However, the degree of keratocyte proliferation was significantly less in the AM group than in the control group at both weeks 4 and 8 .

THICKNESS OF REGENERATED CORNEAL STROMA Using fluorescence microscopy, the subepithelial zone between the epithelium and the DTAF stained stromal bed showed regenerated stromal tissue that had been synthesised after surgery (Fig 3). The thickness of the newly regenerated stromal tissue was significantly thinner in the AM group than in the control group 4 and 8 weeks after surgery (Table 2, p<0.0001). with separation between regression slopes

Table 2 Mean (SD) number of inflammatory cells infiltrated and mean (SD) thickness of the cornea regenerated in the stroma after excimer laser keratectomy

\begin{tabular}{lllll}
\hline & Time after surgery & Control group $(n=6$ eyes $)$ & AM group $(n=6$ eyes $)$ & $p$ value \\
\hline Inflammatory cells $\left(/ 10000 \mu \mathrm{m}^{2}\right)$ & 1 day & $18.7(7.2)$ & $4.3(4.5)$ & $<0.0001$ \\
& 3 days & $5.9(2.4)$ & $3.3(3.1)$ & 0.023 \\
Regenerated stroma $(\mu \mathrm{m})$ & 4 weeks & $40.7(7.9)$ & $26.7(5.0)$ & $<0.0001$ \\
& 8 weeks & $73.9(7.4)$ & $36.2(9.4)$ & $<0.0001$ \\
\hline
\end{tabular}

$\mathrm{AM}=$ amniotic membrane. ${ }^{\star}$ Student's $t$ test. 

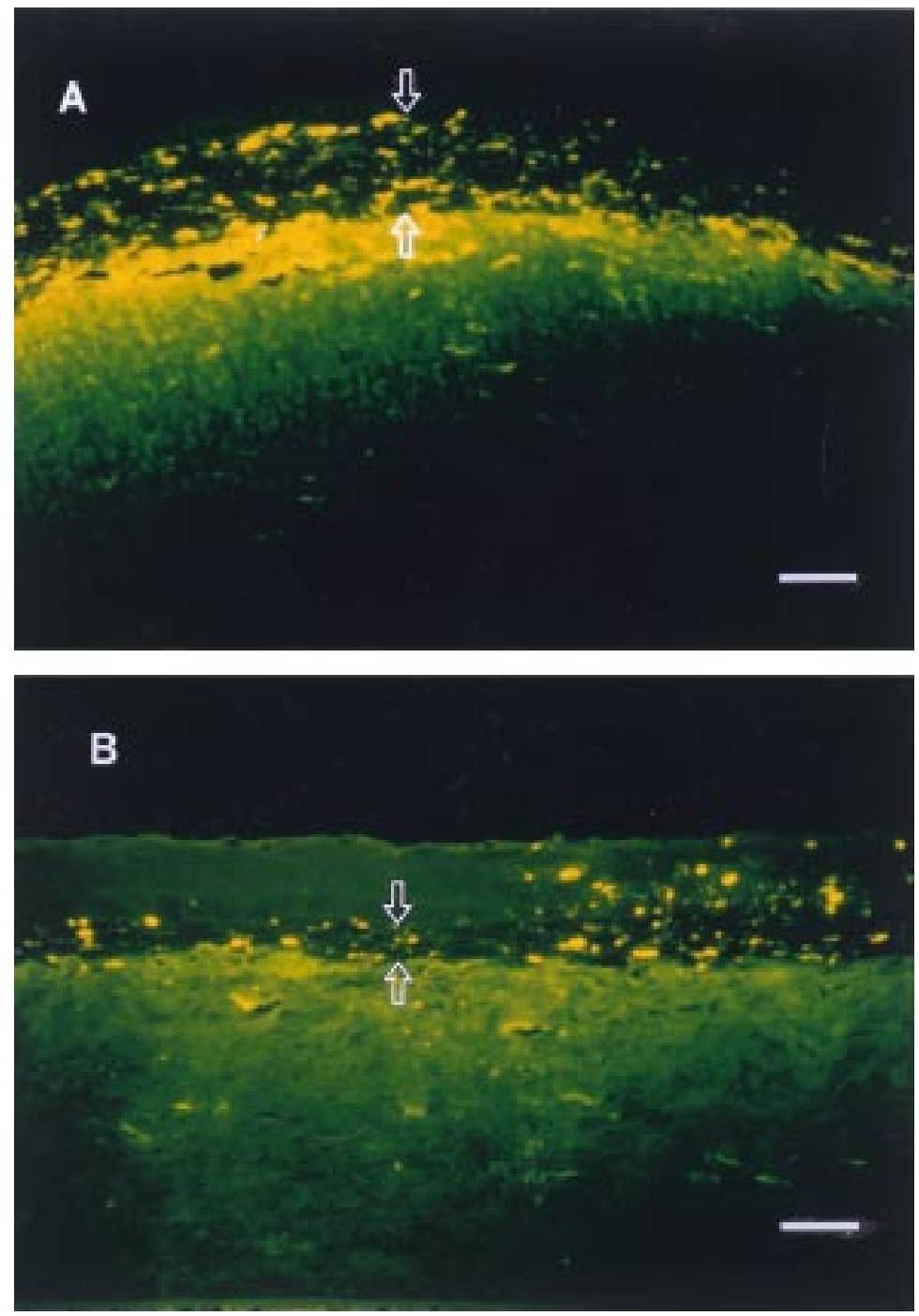

Figure 3 Fluorescence photomicrographs of rabbit corneas at 8 weeks after excimer laser keratectomy (DTAF stain). A significant amount of regenerated collagen (between arrows) dispersed with DTAF dye between the epithelium (upper arrow) and the brightly fluorescent original stromal bed (lower arrow) is present in the control cornea $(A)$ but there is a little unstained collagen (between arrows) in the AM covered cornea (B). Bar $=50 \mu \mathrm{m}$.

ARRANGEMENT OF REGENERATED STROMAL COLLAGEN

In both groups regenerated collagen staining positive for Masson's trichrome stain was observed on the ablated corneal stroma at 8 weeks after surgery. In the AM group the stroma maintained a well arranged lamellar structure and there were fewer keratocytes than in the control group (Fig 4).

\section{Discussion}

Many studies on corneal wound healing following injury to the ocular surface, including excimer laser keratectomy, have focused on inhibiting loss of stromal keratocytes during the early postoperative period. ${ }^{11} 122425$ The anterior stromal keratocytes are lost following removal of the corneal epithelium. ${ }^{11}{ }^{24}$ The presence of the corneal epithelium inhibits the synthesis of connective tissue after keratocyte loss, which may result in less corneal haze. ${ }^{10}{ }^{25}$ Thus, the degree of epithelial healing after a corneal wound is thought to affect stromal remodelling.
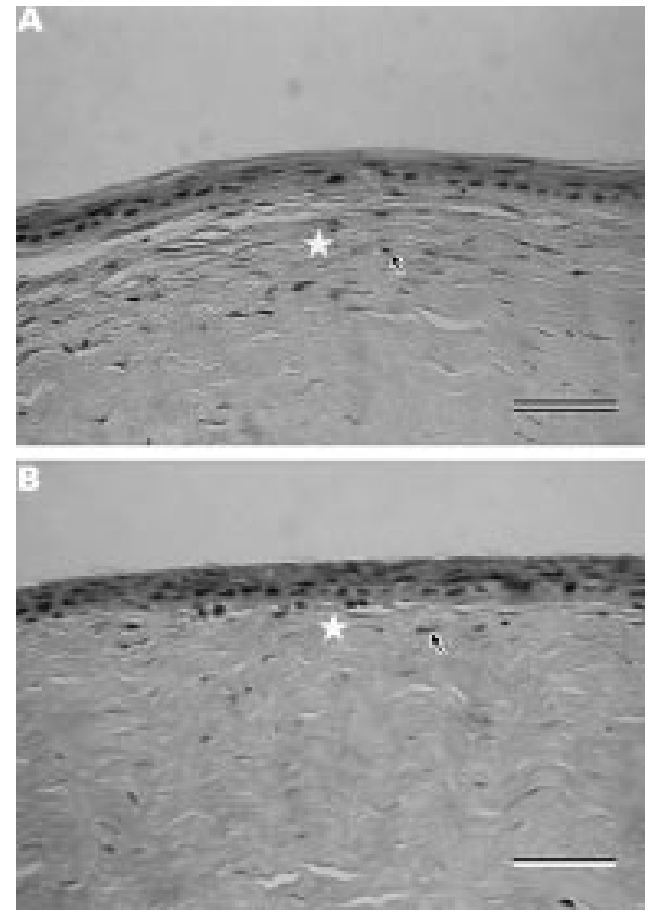

Figure 4 Light micrographs of rabbit corneas at 4 weeks after excimer laser keratectomy (Masson's trichrome stain). The newly formed collagen in the anterior stroma (*) has a more regular architecture in the AM covered cornea (B) than in the control cornea (A). The keratocytes (arrows) beneath the epithelium show less hyperplasia in the AM covered cornea (B) than in the control cornea (A). Bar = $50 \mu \mathrm{m}$.

The effects of AM on epithelial migration have not been fully investigated. Recently, Choi et $a l^{12}$ have shown that the application of the AM had no effect on epithelial healing after PRK. However, our study of the regression rates of the radius, calculated by the formula of Crosson et $a l,{ }^{20}$ has shown different results. We found that the use of AM as a dressing induced rapid re-epithelialisation underneath it during the initial stage of wound healing following PTK (Table 1). Interestingly, in corneas covered with AM we observed a significantly shorter latent phase and more active epithelial migration than in the control group, especially from 6 to 24 hours. Although many events associated with cell migration are less clear, it seems that the AM may promote extensive cellular and subcellular reorganisation of the remaining viable epithelial cells during this time. The results of this study are also thought to support the findings of Koizumi et $a l^{17}$ who reported that the amniotic epithelium of the AM contains several growth factor proteins (EGF, KGF, HGF, and bFGF) which might facilitate epithelial migration.

The stromal inflammatory infiltrate consists mainly of PMNs which may be responsible for induction of keratocyte apoptosis. ${ }^{26}$ Other studies suggest that the application of the AM to a corneal wound after PRK reduces apoptosis in keratocytes ${ }^{27}$ and reduces the inflammatory response. ${ }^{12}$ The AM was thought to play the same role as the corneal epithelium using a mechanical barrier ${ }^{12}$ and basement membrane components in a corneal wound. ${ }^{19}$ Our histological observations have also shown that the 
ablated anterior stroma without epithelium was infiltrated with many inflammatory cells together with a smaller number of keratocytes during the initial stage of wound healing. Although details of the underlying cellular events remain unclear, rapid epithelial healing in the AM covered corneas is also thought to be associated with both a smaller inflammatory response and reduced keratocyte loss during the re-epithelialisation period, together with a marked decrease in the development of haze after re-epithelialisation.

A few days after the corneal wound the remaining keratocytes in the injured stroma begin transformation into activated fibroblasts and migrate into the wounded region so that the subepithelial area becomes hypercellular. $^{72}$ SundarRaj et $a l^{28}$ reported that newly deposited collagen within the subepithelial region lacks the organised lamellar arrangement characteristic of normal lamellar architecture. The ablated cornea will stabilise at $4-8$ weeks. Furthermore, the 1 month period is required for regeneration of new collagen, as shown by Tuft et al. ${ }^{13}$ In our study the number of keratocytes and the degree of haze in the control corneas tended to increase progressively up to 8 weeks after surgery. These results are similar to those reported by Corbett et al. ${ }^{29}$ However, in the AM covered corneas there was less repopulation of keratocytes. Sections examined by DTAF staining showed less thickening of the newly formed stroma over the ablated stromal bed. The newly formed collagen showed relatively more regular architecture at 8 weeks by Masson's trichrome stain. Based on these findings, we consider that the histological changes in the regenerated stroma following a corneal wound are closely associated with less haze in the AM covered corneas. It seems that DTAF staining could be used to study regression of the refractive correction by stromal regrowth after PRK for high myopia.

Although the exact mechanisms of these findings remain to be elucidated, we have shown that the use of AM patches after a corneal wound, including excimer laser surgery in which severe haze is expected, may induce rapid epithelial migration. Subsequently, the AM may inhibit irregular stromal collagen synthesis associated with corneal haze. These findings therefore provide further evidence that the AM may be considered as an effective dressing material for recovery of visual acuity in a variety of corneal wounds including excimer laser keratectomy.

Further studies are needed to investigate the cellular mechanisms and the influence of the $\mathrm{AM}$ on the histological changes of the regenerated epithelium in connection with the development of haze and regression.

The authors have no proprietary or financial interests in any of the materials or methods mentioned in this article.

This work was supported in part by a grant in aid from the Catholic Foundation for Eye Research (CFER), Seoul, Korea.

Presented in part at the Asia Pacific Academy of Ophthalmology, Manila, Philippines, March 1999.

1 Marshall J, Trokel S, Rothery S, et al. A comparative study of corneal incisions induced by diamond and steel knives and two ultraviolet radiations from an excimer laser. $\mathrm{Br} \mathcal{7}$ Ophthalmol 1986;70:482-501.

2 Seiler T, McDonnell PJ. Excimer laser photorefractive keratectomy. Surv Ophthalmol 1995;40:89-118.

3 Moller-Pedersen T, Li HF, Petroll WM, et al. Confocal microscopic characterization of wound repair after photorefractive keratectomy. Invest Ophthalmol Vis Sci 1998;39: 487-501.

4 Siganos DS, Katsanevaki VJ, Pallikaris IG. Correlation of subepithelial haze and refractive regression 1 month after photorefractive keratectomy for myopia. 7 Refract Surg 1999;15:338-42.

5 Gartry D, Kerr Muir M, Marshall J. Excimer laser treatment of corneal surface pathology: a laboratory and clinical study. Br F Ophthalmol 1991;75:258-69.

6 Bohnke M, Thaer A, Schipper I. Confocal microscopy reveals persisting stromal changes after myopic photorefractive keratectomy in zero haze corneas. $\mathrm{Br} \mathcal{F}$ Ophthalmol 1998;82:1393-400.

7 Wu WC, Stark WJ, Green WR. Corneal wound healing after 193-nm excimer laser keratectomy. Arch Ophthalmol 1991; 109:1426-32.

8 Gartry DS, Muir MG, Lohmann CP, et al. The effect of topical corticosteroids on refractive outcome and corneal haze after photorefractive keratectomy. A prospective, randomized, double-blind trial. Arch Ophthalmol 1992;110: $944-52$

9 O'Brart DP, Lohmann CP, Klonos G, et al. The effects of topical corticosteroids and plasmin inhibitors on refractive outcome, haze, and visual performance after photorefractive keratectomy. A prospective, randomized observermasked study. Ophthalmology 1994;101:1565-74.

10 Park CK, Kim JH. Comparison of wound healing after photorefractive keratectomy and laser in situ keratomileusis in rabbits. $\mathcal{F}$ Cataract Refract Surg 1999;25:842-50.

11 Szerenyi KD, Wang X, Gabrielian K, et al. Keratocyte loss and repopulation of anterior corneal stroma after deepithelialization. Arch Ophthalmol 1994;112:973-6.

12 Choi YS, Kim JY, Wee WR, et al. Effect of the application of human amniotic membrane on rabbit corneal wound healing after excimer laser photorefractive keratectomy. Cornea 1998;17:389-95.

13 Tuft SJ, Zabel RW, Marshall J. Corneal repair following keratectomy. A comparison between conventional and laser photoablation. Invest Ophthalmol Vis Sci 1989;30:1769-77.

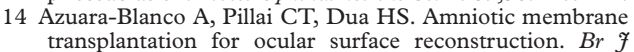
Ophthalmol 1999;83:399-402.

15 Tseng SC, Prabhasawat P, Barton K, et al. Amniotic membrane transplantation with or without limbal allografts for corneal surface reconstruction in patients with limbal stem cell deficiency. Arch Ophthalmol 1999;116:431-41.

16 Shinozaki N, Shoda A, Shimazaki J, et al. Detection of basic fibroblast growth factor (b-FGF) from amniotic membrane. Invest Ophthalmol Vis Sci 1995;36(Suppl):131.

17 Koizumi NJ, Inatomi TJ, Sotozono CJ, et al Growth factor mRNA and protein in preserved human amniotic membrane. Curr Eye Res 2000;20:173-7.

18 Tseng SC, Li DQ, Ma X. Suppression of transforming growth factor-beta isoforms, TGF-beta receptor type II, and myofibroblast differentiation in cultured human corneal and limbal fibroblasts by amniotic membrane matrix. F Cell Physiol 1999;179:325-35.

19 Kim JC, Tseng SC. Transplantation of preserved human amniotic membrane for surface reconstruction in severely damaged rabbit corneas. Cornea 1995;14:473-84

20 Crosson CE, Klyce SD, Beuerman RW. Epithelial wound closure in the rabbit cornea. A biphasic process. Invest Ophthalmol Vis Sci 1986;27:464-73.

21 Fantes FE, Hanna KD, Waring GO, et al. Wound healing after excimer laser keratomileusis (photorefractive keratectomy) in monkey. Arch Ophthalmol 1990;109:665-75.

22 Davison PF, Galbavy EJ. Fluorescent dyes demonstrate the uniform expansion of the growing rabbit cornea. Invest Ophthalmol Vis Sci 1985;26:1202-9.

23 Davison PF, Galbavy EJ. Connective tissue remodeling in corneal and scleral wounds. Invest Ophthalmol Vis Sci 1986; 27:1478-84

24 Latvala T, Tervo K, Mustonen R, et al. Expression of cellular fibronectin and tenascin in the rabbit cornea after excimer laser photorefractive keratectomy: a 12-month study. Br f Ophthalmol 1995;79:65-9.

25 Wilson SE. Molecular cell biology for the refractive corneal surgeon: programmed cell death and wound healing. 7 Refract Surg 1997;13:171-5.

26 Larkin DF, Alexander RA, Cree IA. Infiltrating inflammatory cell phenotypes and apoptosis in ejected human corneal allografts. Eye 1997;11:68-74.

27 Wang M, Gray T, Prabhasawat P, et al. Corneal haze is reduced by amniotic membrane matrix in excimer laser photokeratectomy in rabbits. Invest Ophthalmol Vis Sci 1997;38(suppl):405

28 SundarRaj N, Geiss MJ, Fantes F, et al. Healing of excimer laser ablated monkey corneas. Arch Ophthalmol 1990;108: 1604-10.

29 Corbett MC, Prydal JI, Verma S, et al. An in vivo investigation of the structures responsible for corneal haze after photorefractive keratectomy and their effect on visual function. Ophthalmology 1996;103:1366-80. 